\title{
Postpartum depression in mothers and fathers - an underestimated diagnosis
}

\author{
Anca A. Simionescu ${ }^{1,2}$, Andreea Hetea ${ }^{1}$, Maria Ghita ${ }^{3}$, Ana Maria Alexandra Stanescu ${ }^{1,4}$, \\ Serban Nastasia ${ }^{1,5}$, Dora Boghitoiu1,6 \\ ${ }_{1}^{1}$,Carol Davila“ University of Medicine and Pharmacy, Bucharest, Romania \\ ${ }^{2}$ Department of Obstetrics and Gynecology, Filantropia Hospital, Bucharest, Romania \\ ${ }^{3}$ Individual psychologist cabinet, Bucharest, Romania \\ ${ }^{4}$ Department of Family Medicine, "Carol Davila“ University of Medicine and Pharmacy, Bucharest, Romania \\ ${ }^{5}$ Department of Obstetrics and Gynecology, "Dr. Ion Cantacuzino", Bucharest, Romania \\ ${ }^{6}$ Department of Pediatrics, "Grigore Alexandrescu" Children Emergency Hospital, Bucharest, Romania
}

\begin{abstract}
Postpartum depression remains a significant healthcare priority due to the social and family consequences. Research has shown that both mothers and fathers experience significant psychological changes during pregnancy and postnatally, including depressive disorders. Underdiagnosed in most cases, the short and long-term consequences involve infant and child development, family's life and social disruption. Because this pathology may lead to deviation from behavioural and social norms, we want to emphasize that timely and appropriate diagnostic can improve the effectiveness of treatments and avoid complications. This may contribute to optimal social, emotional and behavioural child development that may occur consecutively to family members" emotional and psychological manifestations.
\end{abstract}

Keywords: depression, postpartum, men's depression, women's depression

\section{BACKGROUND}

Depression remains a major healthcare priority due to the social and family consequences, as well as increased medication use and psychotherapy treatments required. The reported prevalence of major depressive disorders is higher in female at $5.8 \%$ and $3.5 \%$ in males. Regional differences range depending on the economic situation, categories of age, conflict situation related to war or possibilities of registration $(1,2)$.

Postpartum depression (PPD) is considered when depressive episodes and manifestations occur one year after giving birth (3). PPD is different from the transient maternal "postpartum blues" in postpartum, a milder reversible mood disruption within the first weeks after giving birth (4). Postpartum depression has been perceived over time as a problem for women, but recent research has shown that fathers also experience significant changes during pregnancy and postnatally (5). Although pregnancy and childbirth are typically framed as positive life events, parents must adapt to their new status. The immediate birth period is emotionally stressfully for both mother and father. To this is added the pressure of families, grandmothers and grandfathers from different generations, all these becoming emotionally conflicted states that can overexpress the natural capacity of adaptation. Most couples and most societies are not prepared for managing stress in parenthood. Nowadays, society is conflictual and violent. Society is in a state of perpetual conflict and a drastic increase of violence because of globalisation and competition for limited places and resources. COVID-19 pandemics and social isolation were changing people's lives and are an important trigger to depressive disorders.

The prevalence of maternal PPD ranges from around $10-15 \%$ but can be as high as $30 \%$ depending on the criteria operated for diagnosis and for the time period to follow-up $(6,7)$.

Postpartum paternal depression is described mainly in the literature, not being classified as part 
of a syndrome, is little understood by the general population. Postpartum paternal depression is no taught in university.

Some studies have shown that $32.6-47 \%$ of couples included at least one parent who had major depression symptoms in the first two months postpartum, while $60 \%$ of couples had at least one partner who had a depressed state during pregnancy or after childbirth (8).

In the United States, a large study of 12,884 men ranges father depression in the first-year postpartum from $4 \%$ to $25.5 \%$. The prevalence of depression varies from $1.2 \%$ in Ireland to $11.9 \%$ in Brazil. Also, the different percentage worldwide may be related to the use of different scores to measure paternal postpartum depression, cultural, social and economic differences between states (9). The incidence rate of depression among men whose partners have postpartum depression varies from $24 \%$ to $50 \%$ (10).

Psychiatrists have agreed that antenatal depression and/or depression before pregnancy are the leading risk factors for developing PPD $(11,12)$.

Stressful and emotional events in daily life or perception of a stressful life can affect people's mental health, but those prone to depression or other disorders need to understand when they are at risk. Also, doctors may play an essential role in understanding the importance of timely diagnosis and treatment.

\section{MEDICAL, SEXUAL, BEHAVIOURAL CHANGES DURING PREGNANCY AND AFTER CHILDBIRTH}

Pregnancy is associated with anatomical and hormonal changes, birth-related trauma perception( pain during labour, episiotomy), social and partner relationship changes, and it is somewhat easy to understand the consequences for women's mental health, but also for his partner. Birth can also be a stressful experience for the mother and the father.

Researchers have been proved hormonal changes during pregnancy and postpartum for both mother and father.

We already know that hormonal fluctuations largely trigger postpartum depression in mothers, but studies show that a man's hormones also change during pregnancy and after birth. The reasons are still unknown. A study of 193 women has suggested a positive association between testosterone level and the occurrence of PPD symptoms within the first three postpartum days (13). A de- crease and suppressed cellular immunity are founded among depressive mothers(14). Testosterone levels begin to fall few months before giving birth and remain low a few months after birth. However, estrogen levels are low in women after childbirth (15).

In men, fathers involved in parenting registered high levels of estrogen. Prolactin and cortisone also have low values. Decreased estrogen, vasopressin and cortisone cause attachment difficulties between father and child (16).

Prolactin hormone is an anxiolytic with stress-protective properties. A high level of prolactin during breastfeeding may diminuate the stress (17).

In some men, symptoms such as nausea and weight gain also sleep deprivation may be somatic markers for anxiety and depression. The hormonal changes associated with neurochemical changes may determine the perfect context for the onset of postpartum male depression. These are added the anatomical changes of the woman's body that are perceived differently by the two partners.

Several factors are independently linked to antenatal and postpartum depression. Living with parents, socioeconomic difficulties, marital conflicts, and alteration in sexual activity combined with a history of depression and perception of life as stressful largely contributed to depression (1822 ). One prospective study has hounded that one in five women related deterioration of sexual life and a decline of sexual activity in the 18 months after delivery (23). Depression is largely correlated with negative sexual interest and needs, lack of pleasure and of feelings, and lack of coital activity (24). Dysfunctional sexuality involves not only the depressed patients but their partners as well (25).

All these predisposing factors can be added partners' medical problems, history of abortions, alcohol and drug addiction, or an infant with abnormalities.

\section{CONSEQUENCES OF PPD}

Many studies indicated a significant association between maternal and paternal PPD and negative health concerns in infants $(26,27)$. Maternal depressive symptoms in the first months seemed to predict more overall physical health concerns for infants at one year $(28,29)$, proving that is true for all diseases associated with pregnancy, including psychiatric problems, that the mother's health will be reflected in the evolution of the child's health.

Mothers with depressive symptoms were significantly more likely to discontinue breastfeed- 
ing, interrupt exclusive breastfeeding in the first month $(30,31)$, and manifest dissatisfaction with their infant feeding method (32).

Also, it was founded a potential effect of maternal PPD on the birth weight; infants of depressed mothers presented low-birth weight than infants of nondepressed mothers $(28,33,34)$.

Infant diarheea occurring in the first three months of life was associated more with maternal depression $(35,36)$.

The emotional state of a father is also vital in the development of the father-child, father-mother relationship and infant development. Depressed fathers have a higher predisposition to hit their children and cannot play, sing, colour, read or eat with their little ones. Thus, a father with such behaviour can negatively influence the child: when the infant grows up, emotional problems or even developmental delays may occur.

A depressed father makes the mother even more vulnerable in the postpartum period, but if the father participates in the family life, he can help them from experiencing the harmful effects of their mother's depression.

A meta-analysis found that children living with a father suffering from depression or other disorder have a 33-70\% increased risk of developing emotional or behavioural problems. Paternal depression causes increased aggression in children aged 0 to 4 years (37).

The best prediction factor of a man's risk of depression is if his wife is depressed. Studies show that if mothers have postpartum depression, half of their partners will develop some form of postpartum depression. Depression in both parents can lead to devastating consequences for the family and especially for their children.

There is a major difference between women and men, as the latter feel more anxious when they find that the situation has gotten out of control. Men shut themselves out and do not seek help. On the other hand, women tend to socialize, share stories, situations they overcame during pregnancy, and their experiences as mothers.

Men who become fathers for the second time report lower anxiety than those they experienced the first time. Paternal postpartum depression tends to develop more slowly than maternal postpartum depression. Current studies suggest that the rate of depression decreases shortly after birth but increases during the first year. The partner's depression was significantly correlated with the other's depression.

Experts in the field believe that paternal postpartum depression is becoming more common nowadays because this generation of fathers is subjected to social, psychological, and economic stress when deciding to stay home with the baby while the mother goes to work. Traditionally, raising and educating children is a responsibility of the mother, but more recently, fathers want to cese the work to take care of the children and the household chores. A little sleep plus stress and hormonal changes can lead to depression. We must keep in mind that depression is a condition and not a weakness of character.

PPD rates are low, and symptom onset is delayed in countries and cultures that emphasize family support, even during the first weeks in postpartum (38). Also, education, beliefs, personal values have an essential role in forming the family and the role we must have when becoming parents.

\section{SIGNS AND SYMPTOMS FOR PPD}

The symptoms of postpartum depression can be present for weeks or months, and if they are ignored, severe complications may occur. Mother and father manifest the same signs and symptoms, but their expression is different.

Depressed mothers appeared with less estime for the maternal role; they are described as more likely to engage in less-healthy practices with their infant compared to nondepressed mothers, more likely to place their infant in the back-to sleep position, more likely to tell their child stories every day or to participate in activities with them. As depression increased, mothers manifest less favourably their positive affect and are subject to contingent responsiveness, physical intrusiveness, punitive tone, verbal content, and general verbalness (39). High discipline scores are manifested by depressed mothers (40). Also, depressive mothers had negative perceptions of infant patterns to believe that the baby crieses more, sleeps bad, or becomes ill.

Postpartum depressive symptoms appear to lead to negative maternal perceptions of infant patterns, more inclined to report infant crying/fussing, sleeping and temperament problems $(41,42)$.

Depressed fathers are less involved in their children's lives, and this can affect the infants, who may have a mild language delay, disruptive behaviour with social and emotional problems that may manifest later. Men may have different signs of depression. They may not cry, but they may feel frustrated and upset. Fathers may attempt at discouraging their partner from breastfeeding. Lack of sleep and circadian rhythm disturbances, which 
have been associated with symptoms of depression in women, may also increase the risk of postpartum depression in men. Among the symptoms, we also mention sadness, agitation, anger, irritability, violent behaviour, parent-child closeness distance from the partner and the child. He feels worthless, excessive and unjustified guilt or shares suicidal thoughts, presents forgetfulness, difficulty concentration and motivation, decreased libido, weight gain or loss without following any diet. Depressed father has a decreased interest in usual activities or present weakness for certain activities. Moreover, he starts excessive alcohol consumption, drug abuse, gambling, extramarital affairs or other addictive behaviour. He spends more time than usual at work (43). The anxiety and depression can also be translated into violent behaviour towards their partner. Thus, $15 \%$ of women reported violence from their partner, and $69 \%$ of them claimed that this violence was manifested for the first time. $\mathrm{Pa}$ ternal postpartum depression is a risk factor for child abuse and infanticide (9).

The incidence of generalized anxiety disorders ranged from 3.5 to $4.3 \%$, and $5 \%$ of men showed symptoms for five months after birth (44).

The most common psychiatric disorders that occur in postpartum depression are anxiety and obsessive-compulsive disorder. Some studies have found that $95 \%$ of mothers and $80 \%$ of fathers have recurring thoughts about the possibility of harming their children up to the age of 8 months. In the same study, $45 \%$ of fathers reported a concern that their babies could suffocate, about $25 \%$ had a concern about feeding their babies, and 3\%

Conflict of interest: none declared

Financial support: none declared

\section{REFERENCES}

1. Ferrari AJ, Somerville AJ, Baxter AJ, Norman R, Patten SB, Vos T, Whiteford HA. Global variation in the prevalence and incidence of major depressive disorder: a systematic review of the epidemiological literature. Psychol Med. 2013 Mar;43(3):471-81.

2. Angst J, Gamma A, Gastpar M, Lépine JP, Mendlewicz J, Tylee A; Depression Research in European Society Study. Gender differences in depression. Epidemiological findings from the European DEPRES I and II studies. Eur Arch Psychiatry Clin Neurosci. 2002 Oct;252(5):201-9.

3. O'Hara MW, McCabe JE. Postpartum depression: current status and future directions. Annu Rev Clin Psychol. 2013;9:379-407.

4. Grigoriadis S, Romans S. Postpartum psychiatric disorders: What do we know and where do we go? Curr Psychiatry Rev. 2006;2:151-58.

5. Leach LS, Poyser C, Cooklin AR, Giallo R. Prevalence and course of anxiety disorders (and symptom levels) in men across the perinatal period: A systematic review. J Affect Disord. 2016 Jan 15; 190:675-686

6. Darcy JM, Grzywacz JG, Stephens RL, Leng I, Clinch CR, Arcury TA. Maternal depressive symptomatology: 16-month follow-up of infant of men reported a concern about losing their babies. These findings suggest that a psychiatric disorder makes fathers more vulnerable to other psychiatric disorders $(45,46)$.

PPD may be different from puerperal psychosis (PP), a severe psychotic disorder that requires psychiatric management. Low ranging of $\mathrm{PP}$ are reported, from 0.89 to 2.6 in 1,000 women (47). Puerperal psychosis is usually manifested in patients known to have bipolar disorder and have deviated from treatment.

PPD may be differentiated from depression that occurred in hypothyroidism. This is not a usual manifestation of hypothyroidism. Therefore the reported rate of $23 \%$ of women with hypothyroidism manifest symptoms of depression (48), routine screening for thyroid disorders in postpartum is not recommended (49).

PPD may be differentiate from minor depressive symptoms of neurosis, which is actually due to adapting to the new situation. The person with neurosis is aware of his/her problems and difficulties and request to be treated.

\section{CONCLUSIONS}

The diagnosis of postpartum depression requires careful observation of the symptoms and their frequency of occurrence. Also, it may be of maximal importance information about daily behavioural habits, including alcohol, drugs or medication use. Clinicians are encouraged to detect and treat postpartum depression, improving family's behavioural and emotional problems. and maternal health-related quality of life. J Am Board Fam Med. 2011 May-Jun;24(3):249-57.

7. Vesga-López O, Blanco C, Keyes K, Olfson M, Grant BF, Hasin DS. Psychiatric disorders in pregnant and postpartum women in the United States. Arch Gen Psychiatry. 2008 Jul;65(7):805-15.

8. Matthey S, Barnett B, Ungerer J, Waters B. Paternal and maternal depressed mood during the transition to parenthood. $J$ Affect Disord. 2000 Nov;60(2):75-85.

9. Ramchandani P, Stein A, Evans J, O'Connor TG; ALSPAC study team. Paternal depression in the postnatal period and child development: a prospective population study. Lancet. 2005 Jun 25-Jul 1;365(9478):2201-5.

10. Pilyoung K, Swain JE. Sad Dads Paternal Postpartum Depression. Psychiatry (Edgmont). 2007 Feb;4 (2):35-47.

11. O'Hara MW. Postpartum depression: what we know. J Clin Psychol. 2009 Dec;65(12):1258-69.

12. Robertson E, Grace S, Wallington T, Stewart DE. Antenatal risk factors for postpartum depression: a synthesis of recent literature. Gen Hosp Psychiatry. 2004 Jul-Aug;26(4):289-95. 
13. Hohlagschwandtner M, Husslein P, Klier C, Ulm B. Correlation between serum testosterone levels and peripartal mood states. Acta Obstet Gynecol Scand. 2001 Apr;80(4):326-30.

14. Groer MW, Morgan K. Immune, health and endocrine characteristics of depressed postpartum mothers. Psychoneuroendocrinology. 2007 Feb;32(2):133-9.

15. Bloch M, Schmidt PJ, Danaceau M, Murphy J, Nieman L, Rubinow DR. Effects of gonadal steroids in women with a history of postpartum depression. Am J Psychiatry. 2000 Jun; 157(6):924-30.

16. Zarrouf FA, Artz S, Griffith J, Sirbu C, Kommor M. Testosterone and depression: systematic review and meta-analysis. J Psychiatr Pract. 2009 Jul;15(4):289-305

17. Torner $L$, Neumann ID The brain prolactin system: involvement in stress response adaptations in lactation. Stress. 2002 Dec; 5(4):249-57.

18. Robertson E, Grace S, Wallington T, Stewart DE. Antenatal risk factors for postpartum depression: a synthesis of recent literature. Gen Hosp Psychiatry. 2004 Jul-Aug;26(4):289-95.

19. Beck CT. Predictors of postpartum depression: an update. Nurs Res. 2001 Sep-Oct;50(5):275-85.

20. Leigh B, Milgrom J. Risk factors for antenatal depression, postnatal depression and parenting stress. BMC Psychiatry. 2008 Apr 16;8:24.

21. Lewis RW, Fugl-Meyer KS, Bosch R, Fugl-Meyer AR, Laumann EO, Lizza E, Martin-Morales A. Epidemiology/risk factors of sexual dysfunction. J Sex Med. 2004 Jul;1(1):35-9.

22. Bener A, Gerber LM, Sheikh J. Prevalence of psychiatric disorders and associated risk factors in women during their postpartum period: a major public health problem and global comparison. Int J Womens Health. 2012;4:191-200.

23. Faisal-Cury A, Huang H, Chan YF, Menezes PR. The relationship between depressive/anxiety symptoms during pregnancy/postpartum and sexual life decline after delivery. J Sex Med. 2013 May;10(5):1343-9.

24. von Sydow K. Sexuality during pregnancy and after childbirth: a metacontent analysis of 59 studies. J Psychosom Res. 1999 Jul;47(1):27-49.

25. Östman, M. Severe depression and relationships: The effect of mental illness on sexuality. Sexual and Relationship Therapy. 2008;23(4):355-363.

26. Muzik M, Bocknek EL, Broderick A, Richardson P, Rosenblum KL, Thelen K, Seng JS. Mother-infant bonding impairment across the first 6 months postpartum: the primacy of psychopathology in women with childhood abuse and neglect histories. Arch Womens Ment Health. 2013 Feb;16(1):29-38.

27. Lilja G, Edhborg M, Nissen E. Depressive mood in women at childbirth predicts their mood and relationship with infant and partner during the first year postpartum. Scand J Caring Sci. 2012 Jun;26(2):245-53.

28. Gress-Smith JL, Luecken LJ, Lemery-Chalfant K, Howe R. Postpartum depression prevalence and impact on infant health, weight, and sleep in low-income and ethnic minority women and infants. Matern Child Health J. 2012 May;16(4):887-93.

29. Korja R, Savonlahti E, Ahlqvist-Björkroth S, Stolt S, Haataja L, Lapinleimu H, Piha J, Lehtonen L; PIPARI study group. Maternal depression is associated with mother-infant interaction in preterm infants. Acta Paediatr. 2008 Jun;97(6):724-30.

30. Stuebe AM, Grewen K, Meltzer-Brody S. Association between maternal mood and oxytocin response to breastfeeding. J Womens Health (Larchmt). 2013 Apr;22(4):352-61.

31. Feldens CA, Vitolo MR, Rauber F, Cruz LN, Hilgert JB. Risk factors for discontinuing breastfeeding in southern Brazil: a survival analysis. Matern Child Health J. 2012 Aug;16(6):1257-65.
32. Dennis CL, McQueen K. Does maternal postpartum depressive symptomatology influence infant feeding outcomes? Acta Paediatr. 2007 Apr;96(4):590-4.

33. Nasreen HE, Kabir ZN, Forsell Y, Edhborg M. Impact of maternal depressive symptoms and infant temperament on early infant growth and motor development: results from a population based study in Bangladesh. J Affect Disord. 2013 Apr 5;146(2):254-61.

34. Bakare MO, Okoye JO, Obindo JT. Introducing depression and developmental screenings into the national programme on immunization (NPI) in southeast Nigeria: an experimental crosssectional assessment. Gen Hosp Psychiatry. 2014 JanFeb;36(1):105-12.

35. Rahman A, Bunn J, Lovel H, Creed F. Maternal depression increases infant risk of diarrhoeal illness: a cohort study. Arch Dis Child. 2007 Jan;92(1):24-8.

36. Okronipa HE, Marquis GS, Lartey A, Brakohiapa L, Perez-Escamilla R, Mazur RE. Postnatal depression symptoms are associated with increased diarrhea among infants of HIV-positive Ghanaian mothers. AIDS Behav. 2012 Nov;16(8):2216-25.

37. Weitzman M, Rosenthal DG, Liu YH. Paternal depressive symptoms and child behavioral or emotional problems in the United States. Pediatrics. 2011 Dec;128(6):1126-34.

38. Halbreich U. Postpartum disorders: multiple interacting underlying mechanisms and risk factors. J Affect Disord. 2005 Sep;88(1):1-7.

39. Lanzi RG, Bert SC, Jacobs BK; Centers for the Prevention of Child Neglect. Depression among a sample of first-time adolescent and adult mothers. J Child Adolesc Psychiatr Nurs. 2009 Nov; 22(4):194-202

40. Cowley-Malcolm ET, Fairbairn-Dunlop TP, Paterson J, Gao W, Williams M. Child discipline and nurturing practices among a cohort of Pacific mothers living in New Zealand. Pac Health Dialog. 2009 Feb;15(1):36-45.

41. Kerstis B, Engström G, Edlund B, Aarts C. Association between mothers' and fathers' depressive symptoms, sense of coherence and perception of their child's temperament in early parenthood in Sweden. Scand J Public Health. 2013 May;41(3):233-9.

42. Orhon FS, Ulukol B, Soykan A. Postpartum mood disorders and maternal perceptions of infant patterns in well-child follow-up visits. Acta Paediatr. 2007 Dec;96(12):1777-83.

43. Nishimura A, Ohashi K. Risk factors of paternal depression in the early postnatal period in Japan. Nurs Health Sci. 2010 Jun; 12(2):170-6.

44. Paulson JF, Bazemore SD. Prenatal and postpartum depression in fathers and its association with maternal depression: a metaanalysis. JAMA. 2010 May 19;303(19):1961-9.

45. Mayes LC, Swain JE, Leckman JF. Parental attachment systems: Neural circuits, genes, and experiential contributions to parental engagement. Clin Neurosci Res. 2005; 4:301-13.

46. Molyneaux E, Telesia LA, Henshaw C, Boath E, Bradley E, Howard LM. Antidepressants for preventing postnatal depression. Cochrane Database Syst Rev. 2018 Apr 18;4(4):CD004363.

47. VanderKruik R, Barreix M, Chou D, Allen T, Say L, Cohen LS; Maternal Morbidity Working Group. The global prevalence of postpartum psychosis: a systematic review. BMC Psychiatry. 2017 Jul 28;17(1):272.

48. Stagnaro-Green A. Approach to the patient with postpartum thyroiditis. J Clin Endocrinol Metab. 2012 Feb;97(2):334-42.

49. Simionescu AA, Marin E. Postpartum depression and thyroid dysfunction - should pregnant women be screened for thyroid disorders? J Mind Med Sci: 2019:6(1):17. 